\title{
STUDIES ON ANTIMYCOBACTERIAL SUBSTANCES
}

\author{
I. SELECTION OF ANTILEPROUS SUBSTANCES \\ WORTHY FOR CLINICAL TRIAL
}

\author{
Osamu TAMEMASA and Sadae TSUTSUMI \\ (National Institute for Leprosy Research)
}

In view of the lack of adequate methods for the selection of antileprous substances worthy for clinical trial, the authors have been much interested in Bun-Hoi's postulation that substances effective against human leprosy exhibit both antituberculous and antifungal activities, and that these substances are soluble in fat solvents. In this connection about twenty substances known to be antileprous, antituberculous or antifungal were determined of the in vitro antituberculous and antifungal activities, as well as of solubility in fat solvents.

Almost all the substances known to be antileprous showed, though not so strong, definite antituberculous and antifungal activities. Their solubility in fat solvents, however, was not remarkable. Among the tested substances, o-aminophenol was found to possess the properties to satisfy best Buu-Hoi's postulation, but it was ineffective in few cases of lepromatous leprosy. This discrepancy might be due to the specific response of o-aminophenol on the dehydrogenase reaction of Mycobacteria including human and murine leprosy bacilli.

In conculusion, it was difficult to determine whether Buu-Hoi's postulation has any practical use as a screening test for the selection of antileprous substances worthy for clinical test.

\section{抗酸菌病治療剂 の研究 (第 1 報)}

\author{
人治らい実験を試みる価值のある薬物の選択について

為政脩, 堤 貞衛
国立 \\ (1959 年. 8 月 15 日受稿)
}

人らいの実験的化学療法の研究のために試用される薬 物の選択は現在主として, 強力な抗菌作用を有する抗結

核㓮, 抗鼠らい物質, あるいはそれらと近縁の化学構造 を有する化合物の中から行なわれている。人らい菌の試 験管内抗菌力の測定あるいは化学療法的動物実験の不可 能な現状においては，なんらかの次善の選別法の出現す ることが望ましいととは言及するまでもない。この問題
に対して Buu-Hoi 1) は今までに治らい作用の認められ た物質は，抗結核菌作用と抗徽作用を共に有していて， その上脂溶性を有する物質であるとの考察を行つてい る。

著者らはらいの臨床実験に供してみる価值のある薬物 の選択基準に乏しい現在，Buu-Hoi の見解に興味をおぼ えたのであるが，同教授は，DDS，Thibione，大風子油 
脂肪酸, SM, INAH，PAS などの比較的少数の薬物に ついての性質からその結論を下しているにすぎないこと と, 試験管内抗菌力の具体的データーの記載のないこと にふんがみ，さらに多くの菜物について試験管内抗菌力 および脂溶性溶媒に対する溶解性を測定した上，同氏の 見解を検討してみることとした。

\section{実験方法および実験結果}

\section{1）供試薬物}

下記の 21 種の化合物を選えだが，その内相当数の物質 はすでにらいの臨床実験に供せられたことがあるか，あ るい注在治療に用いられており，(No. 1，2，3，4， $8,9,11,12,13,14,15,16,17,18$ (但しそのグリ セッド)，またその他の物澌は試験管内または生体内抗 結核作用(No. 1 11，18，19),抗徽作用(No. 20, 21)の あることの認为ら机ている物質，あるいはまたそれらと なんらかの関係を有する物質である。

(1) p-Aminosalicylic acid (PAS), (2) Dihydrostreptomycin (DHSM), (3) p-Acetylaminobenzaldehyde thiosemicarbazone (Thibione), (4) Isonicotinic acid hydrazide (INAH), (5) Pyrazineamide (PZA), (6) o-Aminophenol (AP $)^{2)}$, (7) Hydroxyprocaine sulfate

(HOP), (8) Hydroxyprocaine-penicillin sulfate (HO PP), (9) Oxymycillin (OM) (=HOPP plus DHSM $)^{3)}$,

(10) Ftivaside (FS), (11) Acidomycin (AM) ${ }^{4}$, (12) Diaminodiphenylsulfone (DDS), (13) Proethyl, (14) Promizole, (15) Promacetin, (16) Dihydrazinodiphenylsulfone (DHDS) ${ }^{5}$, (17) Diaminodiphenylsulfoxide (DD SO), (18) Chaulmoogric acid, (19) $\alpha$-Phenylmyristic acid $^{6)}$ (20) Dehydroacetic acid, (21) Nonylpyrazole ${ }^{7)}$

2）試験管内抗結核菌作用（第 1 表）。

抗結核菌作用の測定は闭本らの ${ }^{2)}$ 方法に順拠して行つ た。培地としては 10\% 馬血清加キルヒナー培養液を用 い, 接種菌量は $\mathrm{H} 37 \mathrm{Rv}$ 株の $37^{\circ} \mathrm{C}, 10$ 日間培養菌の菌 浮遊液 $0.1 \mathrm{mg}$ 学被試験液 $5 \mathrm{cc}$ に接種し， $37^{\circ} \mathrm{C}, 21$ 日 間培養後の結果について, 完全発育阻止濃度と対照の発 育より明かに劣るとみられる不完全発育阻止作用を判定 した。抗菌力を示した表中, 発育阻止濃度の記載のない の注高濃度で薬物の不溶なためである。抗菌力の測定は すべて薬物の同一濃度について 2 本の試験管について観 察した。

\section{3）試験管内抗徽作用（第 2 表）}

Aspergillus niger, Trichophyton mentagrophytes 選び，前者はッァペックとサブローの液体培地について
Tabl 1. In Vitro Antitubercular Activities

\begin{tabular}{|c|c|c|}
\hline \multirow{2}{*}{ Substance } & \multicolumn{2}{|c|}{$\begin{array}{l}\text { Minimum Growth-inhibitory } \\
\text { Concentration }\end{array}$} \\
\hline & $\begin{array}{l}\text { completely } \\
\text { inhibited }\end{array}$ & $\begin{array}{c}\text { imcompletely } \\
\text { inhibited }\end{array}$ \\
\hline 1. PAS & $1: 256.000$ & $1: 1.024 .000$ \\
\hline 2. DHSM & $1: 256.000$ & $1: 1.024 .000$ \\
\hline 3. Thibione & $1: 16.000$ & 1: $\quad 256.000$ \\
\hline 4. INAH & $1: 512.000$ & $1: 2.048 .000$ \\
\hline 5. Pyrazineamide & $1: 4.000$ & 1: $\quad 16.000$ \\
\hline 6. o-Aminophenol & $1: 512.000$ & $1: 1.024 .000$ \\
\hline 7. Hydroxyprocaine sulfate & $1: 256.000$ & $1: 1.024 .000$ \\
\hline $\begin{array}{l}\text { 8. Hydroxyprocaine-penicillin } \\
\text { sulfate }\end{array}$ & $1: 128.000$ & $1: \quad 512.000$ \\
\hline 9. Oxymycillin & $1: 256.000$ & $1: 1.024 .000$ \\
\hline 10. Ftivaside & $1: 256.000$ & $1: 2.048 .000$ \\
\hline 11. Acidomycin & $1: \quad 64.000$ & $1: 1.024 .000$ \\
\hline 12. DDS & $1: \quad 4.000$ & $1: \quad 32.000$ \\
\hline 13. Proethyl & $1: \quad 4.000$ & 16.000 \\
\hline 14. Promizole & 1: $\quad 2.000$ & 8.000 \\
\hline 15. Promacetin & $1: \quad 2.000$ & 4.000 \\
\hline 16. Dihydrazinodiphenylsulfone & $1: \quad 4.000$ & 16.000 \\
\hline 17. Diaminodiphenylsulfoxide & $1: \quad 2.000$ & 8.000 \\
\hline 18. Chaulmoogric acid ( $\mathrm{Na}$ salt) & $1: \quad 8.000$ & 16.000 \\
\hline 19. $\alpha$-Phenylmyristic acid ( $\mathrm{Na}$ salt) & $1: \quad 8.000$ & 32.000 \\
\hline 20. Dehydroacetic acid & $1: \quad 2.000$ & 4.000 \\
\hline 21. Nonylpyrazole & 1: 16.000 & 32.000 \\
\hline
\end{tabular}

Note: Medium-Kirchner's nutrient fluid $(\mathrm{pH} 7.0)$ containing $10 \%$ horse serum.

Bacilli inoculated-M. tuberculosis $\mathrm{H} 37 \mathrm{Rv}, 0.1 \mathrm{mg} / 5 \mathrm{cc}$ mediuum.

Observation-After 21 days at a temp. of $37^{\circ} \mathrm{C}$.

後者は, サブロー培地についてのみ行なつた。菌量は湿 菌量で $0.1 \mathrm{mg} / 5 \mathrm{cc}$ 試験液を接種した。判定はAsp. niger については，ッアペック培地中では $25^{\circ} \mathrm{C}, 3$ 日間後, サブロー培地中では $25^{\circ} \mathrm{C}, 2$ 日間後に行い, Tri. mentogrophytes については $25^{\circ} \mathrm{C}$ ，5日間後に行なつた。 培地の $\mathrm{pH}$ はいずれも 7.0 .

4）脂溶性溶媒に対する溶解性（第 3 表）

物質 $5 \mathrm{mg}$ 学試験管内に科取し， $2 \mathrm{cc}$ の溶媒を加えて 溶解される状態を観察した。

\section{成績の総括と考察}

以上の抗菌力測定の結果から, 現在治らい効果のある とされている薬物は，程度の差はあるが，またいわゆる 抗結核風と比較して微弱ながら一定の試験管内抗結核菌 作用を示し，このことはすでに報告された諸家の実験結 果と一致する。そして抗徽作用については治らい作用を 
Table 2. In Vitro Antifungal Activities

\begin{tabular}{|c|c|c|c|c|c|c|c|c|}
\hline \multirow{4}{*}{ Substansec } & \multicolumn{5}{|c|}{ Aspergillus niger } & \multicolumn{3}{|c|}{ Trichophyton mentagrophyes } \\
\hline & \multicolumn{8}{|c|}{ Minimum Growth-inhibitory Concentration } \\
\hline & \multicolumn{3}{|c|}{ completely inhibited } & \multicolumn{2}{|c|}{ imcompletely inhibited } & $\begin{array}{l}\text { completely } \\
\text { inhibited }\end{array}$ & \multicolumn{2}{|c|}{$\begin{array}{l}\text { imcompletely } \\
\text { inhibited }\end{array}$} \\
\hline & $\begin{array}{l}\text { Czapek's } \\
\text { medium }\end{array}$ & \multicolumn{2}{|c|}{$\begin{array}{l}\text { Sabouroud's } \\
\text { medium }\end{array}$} & $\begin{array}{l}\text { Czapek's } \\
\text { medium }\end{array}$ & $\begin{array}{l}\text { Sabouroud's } \\
\text { medium }\end{array}$ & $\begin{array}{l}\text { Sabouroud's } \\
\text { medium }\end{array}$ & \multicolumn{2}{|c|}{$\begin{array}{l}\text { Sabouroud's } \\
\text { medium }\end{array}$} \\
\hline 1. PAS & & & & $1: \quad 1,000$ & 1: $\quad 1,000$ & & $<1:$ & 1,000 \\
\hline 2. DHSM & & & & $<1: \quad 1,000$ & $<1: \quad 1,000$ & & $1:$ & 2,000 \\
\hline 3. Thibione & & & & $<1: \quad 4,000$ & $<1: \quad 4,000$ & & $<1:$ & 4,000 \\
\hline 4. INAH & & & & $1: \quad 1,000$ & 1,000 & & $<1:$ & 1,000 \\
\hline 5. Pyrazineamide & & & & $1: \quad 1,000$ & $<1: \quad 1,000$ & & $<1:$ & 1,000 \\
\hline 6. o-Aminophenol & $1: \quad 32,000$ & $1:$ & 8,000 & $1: 256,000$ & $1: 32,000$ & $1: \quad 32,000$ & & 28,000 \\
\hline 7. Hydroxyprocaine & $1: \quad 2,000$ & & & $1: \quad 4,000$ & $1: \quad 1,000$ & & $<1:$ & 1,000 \\
\hline 8. Hydroxyprocaine-penicillin sulfate & & & & $1: \quad 1,000$ & $1: \quad 1,000$ & & $<1:$ & 1,000 \\
\hline 9. Oxymycillin & & & & $1: \quad 1,000$ & $1: \quad 1,000$ & & $1:$ & 1,000 \\
\hline 10. Ftivaside & & & & $1: \quad 1,000$ & $1: \quad 1,000$ & & $<1:$ & 2,000 \\
\hline 11. Acidomycin & & & & $1: \quad 8,000$ & $1: \quad 4,000$ & & $1:$ & 1,000 \\
\hline 12. DDS & $1: \quad 2,000$ & & & $1: \quad 4,000$ & $1: \quad 2,000$ & & $<1:$ & 2,000 \\
\hline 13. Proethyl & & & & $1: \quad 2,000$ & $1: \quad 2,000$ & & $<1:$ & 2,000 \\
\hline 14. Promizole & & & & $1: \quad 2,000$ & $1: \quad 2,000$ & & $<1:$ & 2,000 \\
\hline 15. Promacetin & & & & $<1: \quad 1,000$ & $<1: \quad 1,000$ & & $<1:$ & 1,000 \\
\hline 16. Dihydrazinodiphenylsulfone & 2,000 & $1:$ & 2,000 & $1: \quad 4,000$ & 2,000 & 2,000 & $1:$ & 8,000 \\
\hline 17. Diaminodipheny lsulfoxide & & & & $1: \quad 2,000$ & $1: \quad 2,000$ & & $<1:$ & 2,000 \\
\hline 18. Chaulmoogric acid ( $\mathrm{Na}$ salt) & 2,000 & 1: & 2,000 & $1: \quad 4,000$ & $1: \quad 4,000$ & & 1: & 2,000 \\
\hline 19. $\alpha$-Phenylmyristic acid ( $\mathrm{Na}$ salt) & 2,000 & 1: & 2,000 & $1: \quad 4,000$ & $1: \quad 4,000$ & & 1: & 2,000 \\
\hline 20. Dehydroacetic acid & 1: $\quad 2,000$ & $1:$ & 2,000 & $1: 16,000$ & $1: 16,000$ & $1: \quad 4,000$ & $1:$ & 8,000 \\
\hline 21. Nonylpyrazole & $1: 64,000$ & $1:$ & 64,000 & $1: 128,000$ & $1: 128,000$ & $1: 128,000$ & & 12,000 \\
\hline
\end{tabular}

Note: The amount of fungi inoculated $-0.1 \mathrm{mg} / 5 \mathrm{cc}$ medium. Observation-In the case of Asp niger, after 3 days at a temp. of $25^{\circ} \mathrm{C}$ when using Czapek's medium and after 2 days at a temp. of $25^{\circ} \mathrm{C}$ when using Sabouroud's medium. In the case of Tri. mentagrophytes, after 5 days at a temp. of $25^{\circ} \mathrm{C}$ when using Sabouroud's medium.

有するある種の物質は微弱な試験管内発育阻止作用を有 している。即ち DDS, Chaulmoogric acid, Dihydrazinodiphenylsulfone はッアペック培地中の Asp. niger に対 して 1:2,000で完全に発育を阻止し, Promizole, Proethyl, Diaminodiphenylsulfoxide は 1:2,000 で不完全 発育阻止作用をするが，Promacetin は 1：1,000 の濃 度でも発育になんらの影響艺及ぼさない。またこれら物 質は Tri. mentagrcphytes に対して 1:1,000 で完全発 育阻止作用が現わ秃ないかまたは極的て微弱な発育阻止 作用を示すに過ぎない。また一般に，判定の日数は異る のであるが，被試験物質はTri. mentagrophytes に対し てよりAsp.nigerに対してより強く抗徽的に作用する。

脂溶性については，治らい作用のある物質は Chaulmoogra 酸を除いてさほど強い溶解性をもつているとは
考えられない。この性質は，人らい菌がリピッドに富ん で扔り，また多くの菌は脂肪の多い泡沫細胞中にいるの でらいの化学療上重要であるかも知机ない。

試験した物貎のう台には，強い抗結核菌作用とかなり 強力な抗徽作用とを示し, また脂溶性にも富えでいる物 質として o-Aminophenol があり，また抗結核菌作用は 劣るが抗徽作用の強い Nonylpyrazole がある。そこで o-Aminophenol が Buu-Hoi の仮設によく適合する物質 であるので，国立多蘑全生園で原田博士8) が数例の結節 型患者に応用されたがみるべき治療効果は得られなかつ た。またこ礼より数年前に谷奥教授9) 分独自に同物質に ついて行なわれた臨床経験においても治らい作用は認め られなかつた由である。この闍題に関する Buu-Hoi 教 授との馀論 ${ }^{10)}$ において, 同氏が最近らいに有効であるこ 
Table 3. Solubility in Fat Solvents

\begin{tabular}{|c|c|c|c|c|}
\hline Substance & Ether & Acetone & $\begin{array}{l}\text { Chloro- } \\
\text { form }\end{array}$ & Benzen \\
\hline 1. PAS & - & H & - & - \\
\hline 2. DHSM & - & + & - & - \\
\hline 3. Thibione & - & + & - & - \\
\hline 4. INAH & - & + & - & - \\
\hline 5. Pyrazineamide & - & $H$ & \# & - \\
\hline 6. o-Aminophenol & H & H & + & - \\
\hline $\begin{array}{l}\text { 7. Hydroxyprocaine } \\
\text { sulfate }\end{array}$ & - & - & - & - \\
\hline $\begin{array}{l}\text { 8. Hidroxyprocaine- } \\
\text { penicillin sulfate }\end{array}$ & - & - & - & - \\
\hline 9. Oxymycillin & - & 一 & - & - \\
\hline 10. Ftivaside & - & + & - & - \\
\hline 11. Acidomycin & - & + & - & - \\
\hline 12. DDS & - & H & + & - \\
\hline 13. Proethyl & - & $H$ & + & - \\
\hline 14. Promizole & - & H & - & - \\
\hline 15. Promacetin & - & $H$ & - & - \\
\hline $\begin{array}{l}\text { 16. Dihydrayinodiphe- } \\
\text { nylsufone }\end{array}$ & - & + & - & + \\
\hline $\begin{array}{l}\text { 17. Diaminodiphenyl- } \\
\text { sulfoxide }\end{array}$ & - & + & + & + \\
\hline 18. Chaulmoogric acid & $H$ & H & $H$ & H \\
\hline $\begin{array}{l}\text { 19. } \alpha \text {-Phenylmyristic } \\
\text { acid }\end{array}$ & H & H & H & H \\
\hline 20. Dehydroacetic acid & H & $H$ & $H$ & $H$ \\
\hline 21. Nonylpyrazole & $H$ & H & $\#$ & \# \\
\hline
\end{tabular}

Note: -5 Milligrams of a substance is added into $2 \mathrm{cc}$ of a solvent and the solution is permitted to stand for $24 \mathrm{hrs}$. at the room temperature. - - p practically insolubele, + $\cdots$ fairly soluble, $++\cdots$ almost or perfectly soluble.

とを報告したDiphenylthiourea 誘導体が抗徽作用を有す ることからしても自己の見解は依然妥当であると思い， また治らい効果を有する物質は抗結核菌, 抗徽作用なら びに脂溶性を有する物質の中に存在するが，逆にそれら の性睤を具有する物質がすべてらいに有効であるとは考 えていないとの見解を表明した。

最近著者ら ${ }^{11)}$ の研究によると, 上記の o-Aminophenol は鼠らい菌の脱水素に対して影響を与える数少ない物質 の中の一つであり, 従つて o-Aminophenol はらい菌に 対して特殊の作用を有する物質であると考えられるか ら，o-Aminophenol 学 Buu-Hoi の見解の反証として引 用することは不適当であるかも知れない。らい菌の所属 する Mycobacterium は分類学的にも生化学的にも徽と 近縁の関係にあり，依然として Buu-Hoi の見解には興 味が持たれるわけであるが，本実験の範囲で注明確な結 論は得られなかつた。従つて今後出現するであろう抗ら い物質についてこれらの性質を檢討した上で結論を下す のがより妥当であると考えられる。またらいの臨床実験
に供すべき薬物は抗結核菌作用のみでなく，抗㣲試験， 脂溶性試験を行なつて今後の資料とすることが望ましい と思われる。

\section{結 論}

治らい作用を示す物質は抗結核菌作用と抗徽作用を共 有し，脂溶性を有するという Buu-Hoi の見解を検討す る目的で，20余種の治らい凪関係の物質について試験管 内抗結核菌力, 抗徽力抢よび脂溶性空測定した。その結 果，スクリーングテストとして利用文るほどの価值のあ る明確なる関係は得ら机なかつたが，全く価值がないと も断定できなかつた。

本研究を始めるに当り，終始御鞭達を得ている本研究 所小林所長, 義汇研究部長, 東京大学石館教授に染謝し, 実験上の薬物を分与された平野（東京女子医大），石館 (東大), 岡本 (金沢大), 桶田 (日本曹達研), 奥田 (科 研化学), 武田 (東大伝研), 立岡 (武田薬工研) の諸博 士に感謝する。また抗菌力の測定に当り便宜を与えられ た細菌研究公の中山, 林両学士に感謝する。

\section{文献}

1) Buu-Hoi, N. P.: Intern. J. Leprosy 22, 16(1954).

2）Okamoto, H. : 金沢結研年報 4 Appendix (1946).

3) Percy, E.: Intern. J. Leprosy 29, 231 (1955).

4) 佐谷, 西村, 野島, 桜井, 宮崎他: レプラ 24,174 (1955); Intern. J. Leprosy : 23, 124 (1955).

5) Yoshie, Y., Takeda, Y. et al.: Japanese J. Exp. Med. 22317 (1952).

6) 浅野, 本松, 為政: 葙誌 7028 (1950).

7）小菅, 桶田, 寺石, 伊藤, 小坂: 同上 74, 819 (1954).

8）原田：私信

9）谷奥：第29回（1956，4月）日本らい学会総会に おける討論発言

10）ブ・ホイ講演会：1957・5月11日於伝染病研究所 (レプラ 26, 294 (1957) 参照).

11) Tamemasa, O., Tsutsumi, S.: Japanese J. Exp. Med. 28, 183 (1958). 